Н. Б. Гомбоева, Е. Ц. Дугарова. Оценка распространенности дефицита железа у подростков города Улан-Удэ

УДК 616.155.194.8 (571.54)

DOI: $10.18101 / 2306-1995-2020-1-63-74$

\title{
ОЦЕНКА РАСПРОСТРАНЕННОСТИ ДЕФИЦИТА ЖЕЛЕЗА У ПОДРОСТКОВ ГОРОДА УЛАН-УДЭ
}

\section{(C) Гомбоева Наталья Батовна}

старший преподаватель кафедры акушерства и гинекологии

с курсом педиатрии,

Бурятский государственный университет имени Доржи Банзарова

Россия, 670031, г. Улан-Удэ, пр. Строителей, 2а

natalyagom@yandex.ru

\section{(C) Дугарова Екатерина Цырендоржиевна}

врач-ординатор кафедры акушерства и гинекологии

с курсом педиатрии

Бурятский государственный университет имени Доржи Банзарова

Россия, 670031, г. Улан-Удэ, пр. Строителей, 2а

dugarovay@inbox.ru

Благодарность: авторы статьи выражают благодарность сотрудникам лаборатории ГАУЗ «РКБ им. Н. А. Семашко», г. Улан-Удэ.

Аннотация. Дефицит железа у детей является одним из самых распространенных состояний. Цель исследования: оценить распространенность латентного дефицита железа у детей и подростков города Улан-Удэ. Методы: в поперечном (одномоментном) неконтролируемом исследовании изучали содержание сывороточного железа в сыворотке крови у детей и подростков города Улан-Удэ в период с 22 мая по 24 мая 2020 года. Снижение содержания сывороточного железа выявлено у каждого третьего подростка, более выраженное у девушек, и нарастающее с увеличением их возраста, с 38,4\% в возрасте $10-11$ лет до $87,9 \%$ в возрасте $15-17$ лет. При оценке рациона питания подростков выявлена несбалансированность диеты, недостаточное по сравнению с рекомендациями оптимального питания потребление мяса, печени, рыбы, птицы, овощей, фруктов и кисломолочных продуктов; $82,5 \%$ детей пьют значительное количество чая, препятствующего всасыванию поступающего и так в недостаточном количестве железа. 6,6\% подростков не потребляют мясо.

Отмечается высокая распространенность дефицита железа, составившая $46,6 \%$ у обследованных подростков, проживающих в городе Улан-Удэ. Результаты исследования диктуют необходимость принятия организационных мер как по коррекции питания, так и обязательного приема препаратов железа девушками, вступающими в фертильный возраст, разъяснительной работы как среди врачей-педиатров по диагностике железодефи- 
цитных состояний у детей и подростков, так и врачами-педиатрами среди родителей детей и подростков.

Ключевые слова: железо; питание детей; железодефицитные состояния; распространенность; дефицит железа; железодефицитная анемия; подростки.

\section{Для цитирования}

Гомбоева Н. Б., Дугарова Е. Ц. Оценка распространенности дефицита железа у подростков города Улан-Удэ // Вестник Бурятского государственного университета. Медицина и формация. 2020. Вып. 1. С. 63-74.

Адекватная обеспеченность ребенка необходимыми микронутриентами является обязательным условием для растущего организма, обеспечивающих его долголетие за счет снижения рисков формирования различных алиментарно-зависимых социально значимых заболеваний. В документе ВОЗ «Здоровье и питание в Европе. Новая основа для действий» дефицит железа отнесен к наиболее значительно наносящим ущерб здоровью человека, наряду с йодом и витамином А [1]. Железодефицитные анемии (ЖДА) у детей являются одним из самых распространенных заболеваний у детей, и, казалось бы, не представляющими сложности для диагностики и лечения в первичном звене здравоохранения. По данным РМИАЦ Минздрава Республики Бурятия в 2018 году заболеваемость детей в возрасте 0-14 лет ЖДА в Республике Бурятия составила 1889,0, а заболеваемость подростков в возрасте 15-17 лет несколько ниже 1666,0 на 100 тыс. населения соответствующего возраста, то есть ЖДА в республике регистрируется менее, чем у 2\% детей в возрастных группах 0-14 лет и 15-17 лет.

Между тем в Российской Федерации ЖДА регистрируется у 6-40\% детского населения, а по данным ВО3 распространенность анемии у детей 5-12 лет в мире составляет 47\% [2]. Для раннего выявления отклонений в состоянии здоровья каждый ребенок ежегодно проходит профилактический медицинский осмотр с исследованием общего анализа крови (ОАК) у школьников в 7 , $10,15,16,17$ лет. Основным диагностическим критерием для постановки диагноза ЖДА по результатам оценки ОАК является снижение содержания гемоглобина (НB), а также учитываются иные показатели ОАК как количество эритроцитов и ретикулоцитов, содержание и концентрация НВ в них, ширина распределения эритроцитов. Но данное исследование не позволяет своевременно оценить имеющийся дефицит железа в организме ребенка, который остается незамеченным при нормальном содержании показателей ОАК. Согласно клиническим рекомендациям необходимо при подозрении на ЖДА исследовать сывороточные показатели обмена железа - уровня ферритина в крови, уровня трансферрина сыворотки крови, железосвязывающую способность сыворотки (ОЖСС), исследование уровня железа сыворотки крови и 
коэффициент насыщения трансферрина железом (НТЖ), для верификации наличия абсолютного дефицита железа ${ }^{1}$.

Железо является необходимым компонентом многих ферментов в организме, обеспечивающих системный и клеточный аэробный метаболизм, а также окислительно-восстановительный гомеостаз организма. Нормальное содержание железа в организме необходимо для полноценного фагоцитоза, активности клеток-киллеров и бактерицидной способности сыворотки, а также для выработки достаточного количества пропердина, комплемента, лизоцима, интерферона, селективного иммуноглобулина А [2; 3]. При снижении содержания железа ребенок чаще болеет острыми респираторными и иными заболеваниями. В составе гемоглобина железо играет ключевую роль в доставке кислорода к органам и тканям, в первую очередь к головному мозгу. Железо входит в состав ферментов, участвующих в синтезе нейротрансмиттеров (серотонина, допамина, норэпинифрина). При изучении долговременных последствий дефицита железа получена информация не только о снижении когнитивных функций ребенка, но и о снижении социализации ребенка в результате снижения эмоций [4]. Дефицит железа у детей школьного возраста ухудшает познавательные способности, приводит к плохой успеваемости. Поэтому дефицит железа должен своевременно выявляться и корригироваться.

Как известно, железо поступает в организм с продуктами питания, и при соблюдении рекомендаций по оптимальному питанию ребенка, способно обеспечить потребности растущего организма ребенка [5].

Развитию ЖДА предшествует период латентного железодефицита, лабораторным критерием которого служит низкие показатели сывороточного железа на фоне нормального уровня гемоглобина, несмотря на то, что при оценке сывороточного железа выявляется лишь часть железа, циркулирующая в связанном с трансферрином виде, которая может меняться в зависимости от времени приема пищи на $15-20 \%$ в течение суток, так как концентрация трансферрина и общая железосвязывающая способность сыворотки снижаются только при полном истощении депо в организме и не могут быть рекомендованы для ранней диагностики дефицита железа ${ }^{2}[6 ; 7]$.

В соответствии с рекомендациями Всемирной организации здравоохранения в критерии диагностики железодефицитных состояний вклю-

\footnotetext{
1 Железодефицитная анемия: клинические рекомендации. 2020 / Национальное гематологическое общество, Национальное общество детских гематологов и онкологов Федерация лабораторной медицины.

2 Железодефицитная анемия: клинические рекомендации. 2020 / Национальное гематологическое общество, Национальное общество детских гематологов и онкологов Федерация лабораторной медицины.
} 
чен уровень сывороточного железа $<12$ мкмоль/л, и сниженный уровень его содержания в сыворотке крови указывает на имеющийся латентный дефицит железа в организме и требует проведения полного комплекса диагностических мероприятий.

Цель исследования. Оценка содержания сывороточного железа у детей и подростков, проживающих в городе Улан-Удэ.

Методы:

Дизайн исследования: поперечное (одномоментное) неконтролируемое исследование.

Критерии включения:

все обследованные проживают в городе Улан-Удэ; возраст участников соответствовал двум возрастным группам: 10-11 лет (5 класс) и 15-17 лет (9-11 классы); имелось в наличии информированное добровольное согласие родителей у детей в возрасте 10-11 лет и информированное добровольное согласие подростков старше 15 лет на проведение исследования.

Продолжительность исследования:

Период с 22 мая 2020 по 24 мая 2020 года.

Условия проведения.

Все дети проживают в семьях с доходами выше прожиточного минимума; включены в 1 и 2 группы здоровья и не имели изменений в ОАК по результатам профилактических осмотров несовершеннолетних в 2019 году; предоставление родителями детей и подростками информации и ответов на анкету о недельном рационе питания и приеме поливитаминных комплексов.

Оценка содержания железа в сыворотке крови проводилась в лаборатории ГАУЗ «РКБ им.Н.А.Семашко» Министерства здравоохранения Республики Бурятия. Забор крови осуществляли путем венепункции из локтевой вены в одноразовые системы Vacutainer (Bodywin, Китай) в утренние часы (8-11 часов) после 12-14 часового голодания. Доставка биоматериала в лабораторию проводилась с соблюдением температурного режима и условий транспортировки в течение 1 часа после забора.

Оценку результатов обеспеченности железом осуществляли в соответствии с критериями Всемирной организации здравоохранения по диагностике железодефицитных состояний уровня сывороточного железа $<12$ мкмоль/л.

Оценку фактического питания детей в домашних условиях проводили на основании изучения недельного рациона питания детей, проведенного путем анкетирования родителей детей в возрасте 10-11 лет, подростков в возрасте 15-17 лет.

Оценку приема витаминных комплексов проводили на основании анкетирования родителей детей в возрасте 10-11 лет, подростков в возрасте 15-17 лет. 
Н. Б. Гомбоева, Е. Ц. Дугарова. Оценка распространенности дефицита железа у подростков города Улан-Удэ

\section{Этическая экспертиза}

Проведение исследования одобрено Этическим комитетом Медицинского института ФГБОУ ВО «БГУ им. Доржи Банзарова» (протокол №1 от 18.03.2020).

\section{Статистический анализ}

Статистическую обработку данных проводили с использованием пакета программ AtteSTAT, STATISTICA 10.0. Для параметрических количественных данных определяли среднее арифметическое значение (М) и ошибку средней арифметической величины (m). В случае нормального распределения для оценки межгрупповых различий при анализе количественных параметрических данных использовали t-критерий Стьюдента, при аномальном распределении в группах с количественными непараметрическими данными использовался U-критерий Манна-Уитни. Для выявления статистической значимости различий между качественными данными использовали критерий Пирсона $\left(\mathrm{x}^{2}\right)$ с поправками для малых выборок и точный критерий выбора Фишера (если один из показателей был менее 4 , а общее число показателей менее 30 ). Для оценки связи между показателями использовали коэффициенты парной корреляции Пирсона (r) и Кендалла. Различия считались статистически достоверными при $\mathrm{p} \leq 0,05$.

Результаты.

Объекты (участники) исследования.

Нами было обследовано 60 подростков для оценки обеспеченности сывороточным железом в возрасте от 10 до 17 лет, из них юношей - 18,

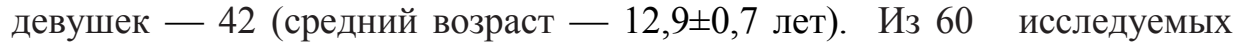
подростков в возрасте 10-11 лет было 28: девушек - 26, юношей -6 , в возрасте 15-17 лет - 32: девушек - 16, юношей -12 .

Основные результаты исследования.

Медианные значения содержания железа в сыворотке крови у девушек и юношей представлены в таблице 1.

Таблица 1

\begin{tabular}{|l|c|c|}
\hline \multicolumn{1}{|c|}{ Показатель } & Девушки & Юноши \\
\hline $\begin{array}{l}\text { Концентрация } \mathrm{Fe}, \\
\text { мкмоль/л }\end{array}$ & $19,9(5,3 ; 25,8 ;)$ & $20,0(10,4 ; 27,5 ;)$ \\
\hline
\end{tabular}

Снижение содержания сывороточного железа выявлено у $33,3 \%$ исследуемых (20 подростков) (диаграмма 1) 


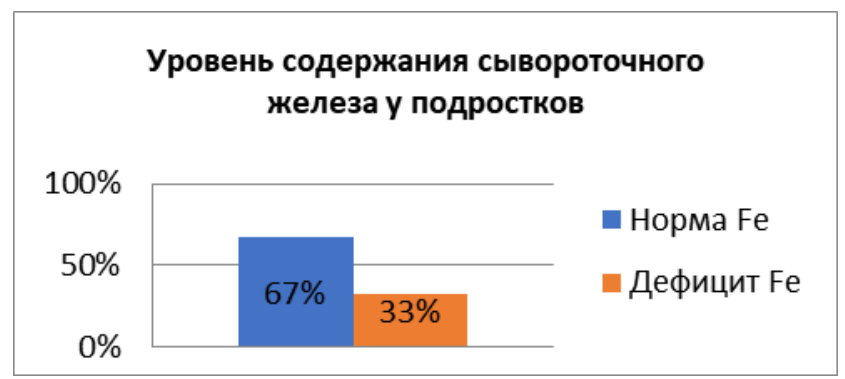

Структура железодефицитного состояния в зависимости от пола представлена в таблице 2.

Таблица 2

\begin{tabular}{|l|c|c|}
\hline \multicolumn{1}{|c|}{ Пол } & Дефицит железа & $\begin{array}{c}\text { Нормальное } \\
\text { содержание железа }\end{array}$ \\
\hline Девушки; $\mathrm{n}=42(\%)$ & $18(42,8)$ & $24(57,2)$ \\
\hline Юноши: $\mathrm{n}=18(\%)$ & $2(11,1)$ & $16(88,9)$ \\
\hline
\end{tabular}

Сравнительная оценка дефицита железа у девушек и юношей представлена на диаграмме 2.

Диаграмма 2

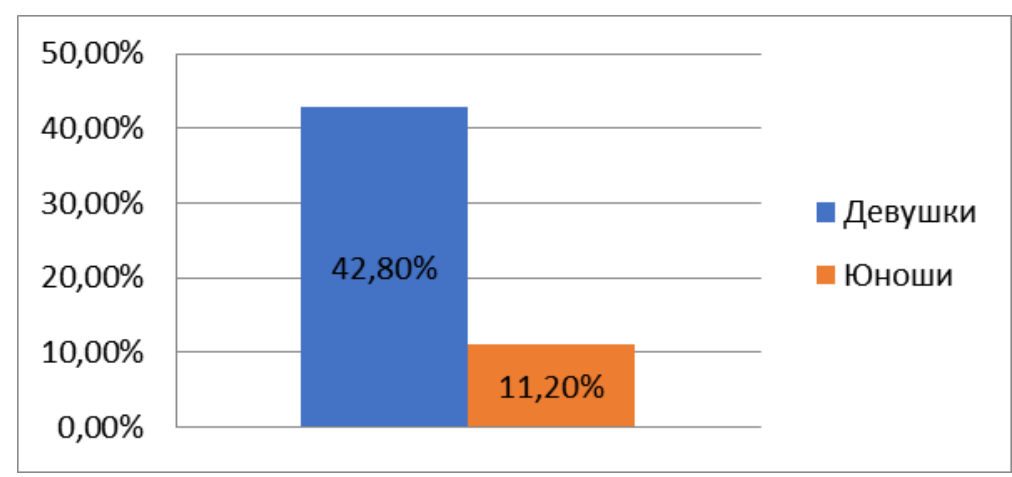

Среднее содержание сывороточного железа у подростков с дефицитом составило $8,62(5,3 ; 12,4)$ мкмоль/л.

Медианные значения содержания железа в сыворотке крови у девушек и юношей с дефицитом железа представлены в таблице 3. 
Н. Б. Гомбоева, Е. Ц. Дугарова. Оценка распространенности дефицита железа у подростков города Улан-Удэ

Таблица 3

\begin{tabular}{|l|c|c|}
\hline \multicolumn{1}{|c|}{ Показатель } & Девушки & Юноши \\
\hline $\begin{array}{l}\text { Концентрация } \mathrm{Fe}, \\
\text { мкмоль/л }\end{array}$ & $8,4(5,3 ; 12,4 ;)$ & $10,5(10,4 ; 10,6)$ \\
\hline
\end{tabular}

Медианные значения содержания железа в сыворотке крови у участников исследования в группе подростков 10-11 и 15-17 лет представлены в таблице 4.

\begin{tabular}{|c|c|c|c|c|}
\hline \multirow{2}{*}{ Показатель } & \multicolumn{4}{|c|}{ Таблица 4} \\
\cline { 2 - 5 } & \multicolumn{2}{|c|}{ Возрастные периоды } \\
\hline & Девушки & Юноши & Девушки & Юноши \\
\hline Концентрация $\mathrm{Fe}$, мкмоль/л & 15,6 & 13,3 & 9,37 & 22,4 \\
\hline
\end{tabular}

Дефицит железа в группе подростков $10-11$ лет составил $37,5 \%$, в группе $15-17$ лет - у 50\%.

При сравнительной оценке дефицит у девушек в группе 10-11 лет составил $38,4 \%$, у мальчиков - 33,3\%, в группе $15-17$ лет дефицит среди девушек составил 87,9\%, у юношей дефицита не выявлено (диаграмма 3 ).

Диаграмма 3

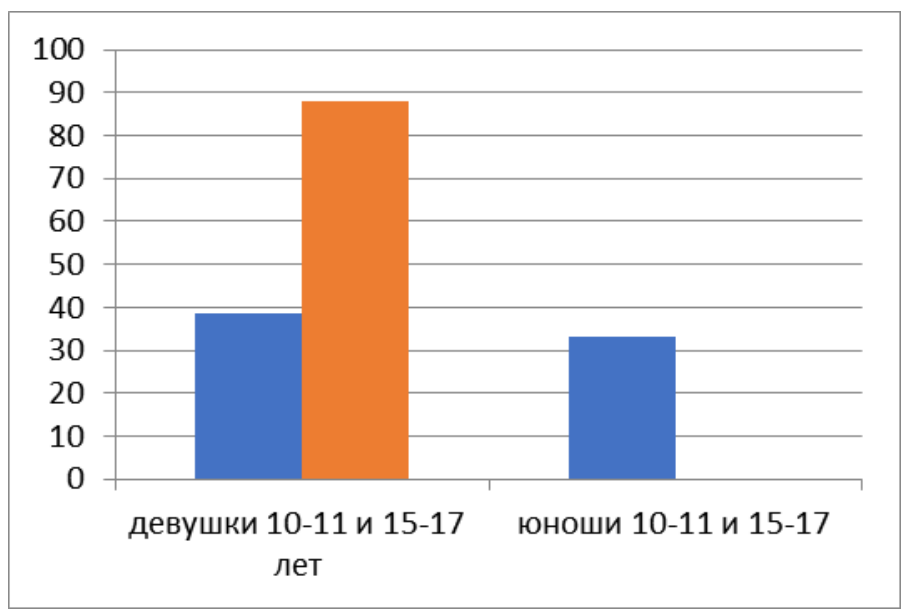

Наиболее высокий дефицит в группе девушек 15-17 лет, среднее содержание железа составило 7,96 мкм/л, у девушек 10-11 лет - среднее содержание было выше и составило 9,0.

Концентрация железа в крови у девочек разных возрастных групп представлена в таблице 5 . 
Таблица 5

\begin{tabular}{|l|c|c|}
\hline \multirow{2}{*}{ Показатель } & \multicolumn{2}{|c|}{ Возрастные периоды } \\
\cline { 2 - 3 } & $10-11$ лет & $15-17$ лет \\
\hline Концентрация $\mathrm{Fe}$, & $9,0(7,8 ; 12,4)$ & $7,96(5,7 ; 11,4)$ \\
\hline
\end{tabular}

Характеристика питания детей и подростков в домашних условиях.

Основным источником железа являются продукты питания, лучше усваивается железо, поступающее в виде гема в мясе, печени, рыбе, птице, значительно ниже биодоступность из растительных продуктов, содержащих негемовое железо ${ }^{1}$ [2].

Для выявления соответствия поступления железа проведен анализ недельного рациона питания детей и подростков.

Физиологическая потребность и рекомендуемые нормы потребления железа (мг) (ВО3).

\begin{tabular}{|c|c|c|c|}
\hline \multicolumn{2}{|c|}{ Возраст } & \multicolumn{2}{|c|}{ Возраст } \\
$10-11$ лет & Девушки & Юноши \\
\hline Девушки, мг & Юноши, мг & 18 & 15 \\
\hline 15 & 12 & \multicolumn{2}{c}{} \\
\hline
\end{tabular}

По результатам анкетирования выявлено недостаточное потребление продуктов, содержащих железо, относительное количество и частота потребления продуктов, содержащих железо, в течение недели представлена в таблице 7.

Таблица 7

Частота потребления продуктов, содержащих железо.

\begin{tabular}{|l|c|c|c|c|c|}
\hline \multirow{2}{*}{ Пищевые продукты } & \multicolumn{5}{|c|}{ Частота потребления, \% } \\
\cline { 2 - 6 } & $\begin{array}{l}\text { 5 раз в } \\
\text { неделю и } \\
\text { чаще }\end{array}$ & $\begin{array}{l}\text { 3 раза в } \\
\text { неделю }\end{array}$ & $\begin{array}{l}\text { 1 раз в } \\
\text { неделю }\end{array}$ & $\begin{array}{l}\text { 1 раз в } \\
\text { месяц }\end{array}$ & Никогда \\
\hline Мясо & 60,0 & 26,6 & 6,6 & 0 & 6,6 \\
\hline Печень & 0 & 0 & 5,0 & 43,3 & 18,3 \\
\hline Рыба & 0 & 0 & 16,6 & 60,0 & 20 \\
\hline Птица & 0 & 0 & 65 & 28,4 & 6,6 \\
\hline Овощи, фрукты & 75 & 6,1 & 16,60 & 0 & 3,3 \\
\hline
\end{tabular}

\footnotetext{
${ }^{1}$ Национальная программа по оптимизации обеспеченности витаминами и минеральными веществами детей России (и использованию витаминных и витаминноминеральных комплексов и обогащенных продуктов в педиатрической практике). М.: Педиатръ; 2017. 152 с.
} 
Н. Б. Гомбоева, Е. Ц. Дугарова. Оценка распространенности дефицита железа у подростков города Улан-Удэ

Лишь $60 \%$ детей потребляют мясо 5 раз в неделю и чаще. Совсем не едят мясо из возрастной группы 10-11 лет 4 подростка, при этом уровень сывороточного железа у этих детей оказался ниже $7,2 \pm 2,3$ мкмоль/л. Отмечено недостаточное по сравнению с рекомендациями оптимального питания потребление печени, рыбы и птицы [5]. Биологическая доступность железа повышается при потреблении с витамином С, находящимся во фруктах и овощах. Несмотря на рекомендации по потреблению 4-5 порций овощей и фруктов ежедневно, не все дети потребляли их ежедневно, лишь $75 \%$ имели в рационе 5 и более раз в неделю фрукты и овощи, но у всех подростков потребление составляло менее 4-5 порций. Кисломолочные продукты, повышающие абсорбцию железа, были в ежедневном рационе лишь у $46,6 \%$ детей [8].

$16,6 \%$ детей потребляли молоко только с чаем (региональные традиции чаепития). $83,3 \%$ детей ежедневно потребляли от 2 до 4 чашек чая, содержащий танин, который снижает всасывание железа на 62\% [9].

Таким образом, отмечено недостаточное поступление железа с пищей у $40 \%$ детей.

Ни один из 60 исследуемых детей не принимал препарат железа в течение последних 12 месяцев, принимали поливитаминные комплексы $52(86,6 \%)$ детей и подростков, совсем не принимали 8 (13,3\%) детей и подростков.

Таблица 7

Частота приема поливитаминных комплексов детьми и подростками за последние 12 месяцев.

\begin{tabular}{|l|c|c|c|c|c|}
\hline & \multicolumn{5}{|c|}{ Частота приема (продолжительностью 1 мес.), \% } \\
\cline { 2 - 6 } & 1 раз & 2 раза & 3 раза & 4 раза & $\begin{array}{c}\text { Совсем } \\
\text { не принимали }\end{array}$ \\
\hline $\begin{array}{l}\text { Прием поливитамин- } \\
\text { ных комплексов }\end{array}$ & 15 & 58,40 & 0 & 5,00 & 21,60 \\
\hline $\begin{array}{l}\text { Прием препарата желе- } \\
\text { за }\end{array}$ & 0 & 0 & 0 & 0 & 100 \\
\hline
\end{tabular}

По результатам анкетирования детей и родителей поливитаминные комплексы в течение последних 12 месяцев продолжительностью 1 месяц принимали 2 раза в год - $35(58,3 \%)$ детей, 1 раз в год - $9(15 \%), 4$ раза в год по 1 месяцу - 3 (5\%), совсем не принимали - 13(15\%) детей.

Данные анкетирования родителей детей и подростков о приеме поливитаминных комплексов превышают данные Росстата, согласно которым лишь $46,3 \%$ детей и подростков принимают поливитаминные комплексы. По нашим данным поливитаминные комплексы принимали 86,6\% исследуемых детей и подростков в течение последних 12 месяцев, но все же 
продолжительность их приема является недостаточной. У 5 не принимавших поливитаминные комплексы уровень железа оказался ниже и составил 7,3+2,1 мкмоль ไл.

Обсуждение

Результаты исследования продемонстрировали высокую распространенность дефицита железа у подростков города Улан-Удэ. Несмотря на нормальные показатели содержания НВ в клиническом анализе крови по результатам профилактических осмотров у 33,3\% исследуемых подростков в возрасте от 10 до 17 лет был снижен уровень сывороточного железа, более выраженный у девушек, с возрастанием по мере увеличения возраста, объясняемый физиологическими потерями с менструациями, с 38,4\% в возрасте 10-11 лет до 87,9\% в возрасте 15-17 лет. Отсутствует дефицит железа у юношей в возрасте 15-17 лет.

Питание у большинства подростков не соответствует рекомендуемым нормам, и не восполняет физиологическую потребность в железе, отмечается недостаточное потребление мяса, рыбы, птицы. Высока распространенность вегетарианства среди подростков (6,6\%). Частое потребление чая, традиционное для республики, и недостаточное потребление кисломолочных продуктов, овощей и фруктов, также являются факторами, снижающими усвоение железа.

Недостаточное количество подростков принимают витаминноминеральные комплексы, в состав которых входит железо.

Особую озабоченность вызывает нарастание дефицита железа у девушек, вступающих в фертильный возраст, и при отсутствии коррекции, неизбежно приводящий к развитию ЖДА. По данным ВО3, наиболее подвержены ЖДА дети раннего возраста и беременные.

В целом результаты исследования требуют проведения организационных мер как по коррекции питания, так и приема препаратов железа, разъяснительной работы врачами-педиатрами среди родителей детей и подростков.

Ограничение исследования

Недостаточное количество юношей в возрасте 10-11 лет, могло повлиять на результаты.

\section{Заключение}

Результаты исследования продемонстрировали высокую распространенность дефицита железа у подростков города Улан-Удэ, не выявляемую при проведении профилактических осмотров несовершеннолетних. Полученные данные требуют повышенного внимания врачей-педиатров по выявлению клинических признаков дефицита железа для расширения перечня исследований по диагностике ЖДС и разъяснительной работы среди подростков и их родителей по организации оптимального питания. 
Н. Б. Гомбоева, Е. Ц. Дугарова. Оценка распространенности дефицита железа у подростков города Улан-Удэ

\section{Источник финансирования}

Исследование проведено на средства гранта инициативных исследований ФГБОУ ВО «Бурятский государственный университет им. Доржи Банзарова» Министерства науки и высшего образования Российской Федерации.

Конфликт интересов.

Авторы статьи подтверждают отсутствие конфликта интересов, о которых необходимо сообщить.

\section{Литература}

1. Robertson A., Tirado C., Lobstein T. et al, ed. Food and health in Europe: a new basis for action [Internet] // WHO Regional Office for Europe; 2004. № 1. Р. 19-28.

2. Румянцев А. Г. Детская гематология: практическое руководство. М.: ГЭОТАР-МЕД, 2015. $658 \mathrm{c}$.

3. Иммунофармакология микроэлементов / А. В. Кудрин [и др.]. М.: KMK, 2000. $537 \mathrm{c}$.

4. Lozoff B., Jimenez E., Smith J. B. Double burden of iron deficiency in infancy and low socioeconomic status: a longitudinal analysis of cognitive test scores to age 19 years // Arch Pediatr Adolesc Med. 2006. № 160(11). Pp. 1108-1113.

5. Батурин А. К., Погожева А. В., Сазонова О. В. Основы здорового питания: образовательная программа для студентов медицинских вузов и врачей Центров здоровья: метод. пособие / Минзравсоцразвития РФ, ГОУ ВПО «СамГМУ». М.: Право, 2011. С. 80.

6. Самчук П. М., Ищенко А. И., Розалиева Ю. Ю. Органосохраняющие технологии при гнойных воспалительных осложнениях кесарева сечения // Вопросы гинекологии, акушерства и перинатологии. 2020. № 19(2). C. 69-103.

7. Самчук П. М., Азоева Э. Л., Розалиева Ю. Ю. Плацентарные нарушения при беременности, после реконструктивных операций на матке // Международный научно-исследовательский журнал. 2019. № 12(90). C. 215-220.

8. Fleischer Michaelsen K., Weaver L., Branca F., Robertson A. Feeding and nutrition of infants and young children: Guidelines for the WHO European Region, with emphasis on the former Soviet countries // WHO Regional Publications, European Series. No 87. P. 45-54.

9. Hallberg L., Rossander L. Effect of different drinks on the absorption of non-heme iron from compositemeals // Hum Nutr Appl Nutr. 1982. № 36(2). P. 116-123. 


\section{ASSESSMENT OF THE PREVALENCE OF IRON DEFICIENCY IN CHILDREN AND ADOLESCENTS IN THE CITY OF ULAN-UDE.}

\section{Gomboeva N. Batovna}

senior lecturer at the Department

of Obstetrics and Gynecology with a course of pediatrics

Dorzhi Banzarov Buryat State University

2a, Stroiteley ave., 670031, Ulan-Ude, Russia

natalyagom@yandex.ru

\section{Dugarova E. Tsyrendorzhievna}

resident doctor, Department of Obstetrics and Gynecology

with a course of pediatrics

Dorzhi Banzarov Buryat State University

2a, Stroiteley ave., 670031, Ulan-Ude, Russia

dugarovay@inbox.ru,

Abstract. Iron deficiency in children is one of common conditions. Objective: to assess the prevalence of iron deficiency in children and adolescents in the city of Ulan-Ude. Methods: in a transverse (simultaneous) uncontrolled study, the serum iron content in the blood serum was studied in children and adolescents in the city of Ulan-Ude from May 22 to May 24, 2020. A decrease in serum iron was detected in every third teenager, more pronounced in girls, and increasing age, from $38,4 \%$ at the age of $10-11$ years old to $87,9 \%$ at the age of $15-17$ years. When assessing the diet of children and adolescents, an unbalanced diet was revealed, insufficient consumption of meat, liver, fish and poultry, vegetables and fruits, sour-milk products compared to the recommendations of optimal nutrition, $82,5 \%$ of children drink a significant amount of tea, which impedes the intake of insufficient amount of iron.6,6\% do not consume meat. Conclusion: there is a high prevalence of iron deficiency, accounting for $46,6 \%$ of the examined in children and adolescents living in the city of Ulan-Ude. The results of the study dictate the need of organization measures to both correct nutrition and mandatory intake of iron preparations by girls entering fertile age, as well as explanatory work among pediatricians to diagnose iron deficiency conditions in children and adolescents, and pediatricians among parents of children and teenagers.

Keywords: iron; children's nutrition; iron deficiency conditions; prevalence; iron deficiency; iron deficiency anemia; iron preparations; adolescents. 